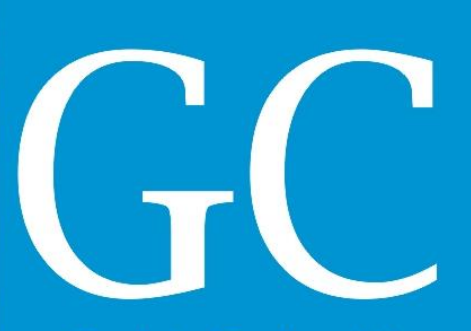

Revista Nacional de Gerenciamento de Cidades
ISSN 2318-8472

v. 08, n. 56,2020

\title{
Avaliação de planos de saneamento básico em municípios do sudeste Brasileiro
}

Evaluation of sanitation plans in southeast Brazilian municipalities

evaluación de planes de saneamiento en municipios del sureste de Brasil

\author{
Katia Sakihama Ventura \\ Professora Doutora, UFSCar, Brasil \\ katiaventura@yahoo.com
}

Leilane Renovato Albuquerque Mestre em Engenharia Urbana, UFSCar, Brasil leilane_renovato@hotmail.com 





\section{Revista Nacional de}

Gerenciamento de Cidades

Quadro 2 - Critérios de avaliação de indicadores do IQ

\begin{tabular}{|c|c|c|c|}
\hline Critério & Resumo & Ação & Nota \\
\hline \multirow{2}{*}{ Atendimento (ATD) } & \multirow{2}{*}{$\begin{array}{l}\text { Variável dicotômica* que avalia se o item } \\
\text { foi atendido ou não }\end{array}$} & Atendimento & 1 \\
\hline & & Não atendimento & 0 \\
\hline \multirow{2}{*}{ Suficiência (SUF) } & \multirow{2}{*}{$\begin{array}{l}\text { Variável dicotômica que avalia se o item } \\
\text { analisado foi abordado suficientemente }\end{array}$} & Abordagem suficiente & 2 \\
\hline & & Abordagem insuficiente & 1 \\
\hline \multirow{3}{*}{ Avaliação (AVA) } & \multirow{3}{*}{$\begin{array}{l}\text { Variável quantitativa que avalia o quanto o } \\
\text { item atendido foi suficientemente } \\
\text { abordado }\end{array}$} & Bom & 3 \\
\hline & & Regular & 2 \\
\hline & & Ruim & 1 \\
\hline
\end{tabular}

* Conceito que, por divisão lógica, se divide em dois, normalmente opostos (sim ou não). Fonte: Daronco (2014)

Quadro 3 -Atribuição de notas para os critérios (ATD, SUF, AVA) de avaliação do IQ

\begin{tabular}{|c|l|l|}
\hline $\begin{array}{c}\text { Nota resultante do } \\
\text { produtório dos critérios }\end{array}$ & \multicolumn{1}{|c|}{ Ação } & $\begin{array}{c}\text { Representação } \\
\text { visual (cor) }\end{array}$ \\
\hline 4 ou 6 & Item atendido & Verde \\
\hline 2 & Item necessita de melhoria & Amarelo \\
\hline 0 ou 1 & Item não foi atendido e necessita ser refeito & Vermelho \\
\hline \multicolumn{2}{|c|}{ Fonte: Organizado pelas autoras com base em Daronco (2014). } \\
\hline
\end{tabular}

A partir dos resultados do IQ, elaborou-se o Dashboard (painel de visualização dos indicadores) com as notas dos planos, de modo a auxiliar a análise dos pontos fortes e as fragilidades de cada um. Para verificar os indicadores quantitativos de saneamento, a base de dados para o cálculo do IA foi a publicação do Sistema Nacional de Informações sobre Saneamento (SNIS), os dados disponíveis em pesquisas do Instituto Brasileiro de Geografia e Estatística (IBGE) e outros provenientes do gestor (prefeitura ou autarquia) do serviço.

O cálculo de cada indicador foi composto por equações e subindicadores específicos, como detalhados por Daronco (2014). Portanto, o presente artigo considerou a avaliação de quatro planos de saneamento pela análise dos 40 subindicadores que compõem o IQ.

\section{RESULTADOS}

A seguir, apresentam-se os resultados qualitativos e quantitativos dos planos analisados.

\section{Revisão da literatura sobre avaliação de planos de saneamento}

Mais de $30 \%$ dos municípios brasileiros estão sem planos constituídos (Brasil, 2017) e com a revisão de literatura, observou-se as principais falhas que podem estar contidas nos PMSBs existentes, como consta no Quadro 4. 


\section{Revista Nacional de}

Gerenciamento de Cidades

Quadro 4 - Falhas gerais observadas em planos municipais de saneamento.

\begin{tabular}{|c|c|}
\hline Falhas & Referência \\
\hline $\begin{array}{l}1-\text { Carência de mecanismos e } \\
\text { procedimentos para avaliação e revisão de } \\
\text { planos }\end{array}$ & $\begin{array}{l}\text { Brasil (2007); Pereira e Heller (2015); Souza e Galvão } \\
\text { Junior (2016); Ventura e Farias (2017); Silva (2019) }\end{array}$ \\
\hline $\begin{array}{l}2 \text { - Ausência de compatibilização entre } \\
\text { medidas estruturais e estruturantes }\end{array}$ & Galvão Junior (2013); Souza (2018) \\
\hline $\begin{array}{l}3 \text { - Conteúdos não relacionados com a } \\
\text { realidade local }\end{array}$ & $\begin{array}{l}\text { Braga (1995); Galvão Junior (2015); Souza e Galvão Junior } \\
\text { (2016); Silva, Imbrosi, Nogueira (2017); Silva (2019) }\end{array}$ \\
\hline $\begin{array}{l}4 \text { - Falta de informações detalhadas e } \\
\text { específicas, considerando o conteúdo } \\
\text { mínimo (artigo 19) da Lei do Saneamento }\end{array}$ & $\begin{array}{l}\text { Muniz (2014); Baracho (2015); Ventura e Farias (2017); } \\
\text { Souza e Galvão Junior (2013); Silva, Imbrosi, Nogueira } \\
\text { (2017); Brito e Araújo (2017); Costa e Reis (2017) }\end{array}$ \\
\hline 5 - Elaboração para cumprimento legal & Braga (1995) \\
\hline $\begin{array}{l}6 \text { - Direcionamento para obtenção de } \\
\text { recurso governamental }\end{array}$ & Braga (1995) \\
\hline $\begin{array}{l}7 \text { - Ausência de compatibilização com } \\
\text { outros planos setoriais e Plansab }\end{array}$ & Brito e Araújo (2017); Silva, Imbrosi, Nogueira (2017) \\
\hline $\begin{array}{l}\text { 8- Falta de interesse e estrutura de gestão } \\
\text { para elaboração do plano de saneamento }\end{array}$ & Braga (1995); Souza e Galvão Junior (2016) \\
\hline $\begin{array}{l}9 \text { - Ausência da participação social e do } \\
\text { poder público }\end{array}$ & $\begin{array}{l}\text { Braga (1995); Baracho (2015); Ventura e Farias (2017); } \\
\text { Pereira e Heller (2015); Souza (2018) }\end{array}$ \\
\hline $\begin{array}{l}10 \text { - Conteúdo semelhante ou idêntico em } \\
\text { planos da mesma bacia hidrográfica }\end{array}$ & Ventura e Farias (2017) \\
\hline $\begin{array}{l}11 \text { - Ausência de abordagem da área rural, } \\
\text { comunidades tradicionais e baixa renda }\end{array}$ & Costa e Reis (2017); Silva (2019) \\
\hline 12 - Falta de definição de ação prioritária & Souza e Galvão Junior (2016); Souza (2018); Silva (2019) \\
\hline
\end{tabular}

Fonte: presentes autoras, 2019

Torna-se evidente que, após 12 anos de existência da Lei de Saneamento, planos são concebidos com informações básicas ausentes e sem detalhamento apropriado, bem como há falta de clareza quanto à participação da sociedade e da administração pública no contexto planejado. Outro item foi a ausência de mecanismos para avaliação do planejamento. Além disto, outros fatores (Quadro 5) associados à gestão do serviço no setor intensificam tais falhas. 


\section{Revista Nacional de}

Gerenciamento de Cidades

Quadro 5 - Dificuldades da gestão do serviço de saneamento.

\begin{tabular}{|l|l|}
\hline Aspectos gerenciais & Referências \\
\hline $\begin{array}{l}1 \text { - Carência de recursos financeiros para obras, } \\
\text { serviços e medidas de apoio para o saneamento }\end{array}$ & $\begin{array}{l}\text { Lisboa, Heller e Silveira (2013); Souza e Galvão } \\
\text { Junior (2016) }\end{array}$ \\
\hline 2 - Número insuficiente de profissionais na área & Lisboa, Heller e Silveira (2013) \\
\hline $\begin{array}{l}\text { especializados ou elaboração de planos } \\
\text { - Baixa qualificacão para execucão de serviços }\end{array}$ & $\begin{array}{l}\text { Lisboa, Heller e Silveira (2013) } \\
\text { Muniz (2014); Souza e Galvão Junior (2016) }\end{array}$ \\
\hline $\begin{array}{l}\text { discussão, acompanhamento e desenvolvimento de } \\
\text { plano }\end{array}$ & Muniz (2014); Souza e Galvão Junior (2016) \\
\hline
\end{tabular}

Fonte: presentes autoras, 2019.

Portanto, é notório que o conteúdo dos planos de saneamento está sendo elaborado conforme a importância dada pela municipalidade. Por isto, é essencial que haja, de fato, apropriação do plano como elemento de planejamento para integrar a participação de distintos atores sociais e considerar as falhas e as dificuldades supracitadas.

\section{Municípios Selecionados}

Após a leitura e estudo prévio dos itens considerados, os planos selecionados e que atenderam aos critérios estabelecidos encontram-se na Tabela 1.

Tabela 1 - Municípios selecionados para avaliação

\begin{tabular}{lll} 
Município - Estado & População (habitantes) & $\begin{array}{l}\text { Bacia Hidrográfica } \\
\text { municípios) }\end{array}$ \\
\hline Canápolis - MG & 12.062 & Baixo Paranaíba (13) \\
Charqueada - SP & 16.608 & Piracicaba, Capivari, Jundiaí - PCJ (57) \\
Iconha - ES & 13.904 & Rio Benevente (06) \\
Moema -MG & 7.487 & Alto São Francisco (29) \\
\hline
\end{tabular}

Fonte: BRASIL, 2010.

O propósito deste estudo foi investigar a aplicabilidade da ferramenta para identificar os pontos frágeis de cada plano. Assim, o intuito não foi comparar os documentos analisados e sim, identificar a carência de informações contidas neles. Cada município foi representado por uma letra do alfabeto ( $, B, C$ e D) e apresentado em ordem distinta daquela organizada na Tabela 1.

\section{Planos avaliados pelo Índice de Qualidade - IQ (10 indicadores e 40 subindicadores)}

É possível que existam outros documentos que estejam impressos nas prefeituras e autarquias, cujas informações não constam nos planos municipais. Porém, a análise de materiais complementares não foi considerada pelos pesquisadores por entender que a disponibilização do plano municipal em mídia digital é condição precípua para transparência ao munícipe. 


\section{Revista Nacional de} Gerenciamento de Cidades

Tabela 2 - Resultado da aplicação do IQ nos PMSBs selecionados

\begin{tabular}{lllll}
\hline \multirow{2}{*}{ Indicador } & \multicolumn{3}{c}{ Nota dos PMSBs por Município } \\
& A & B & C & D \\
\hline IQ-1: Participação da sociedade & 6 & 6 & 6 & 2 \\
IQ-2: Diagnóstico dos serviços de saneamento básico & 6 & 4 & 6 & 6 \\
IQ-3: Avaliação periódica do PMSB & 4 & 4 & 4 & 6 \\
IQ-4: Objetivos, metas e ações para universalização & 2 & 6 & 6 & 6 \\
IQ-5: Comitê gestor do PMSB & 6 & 4 & 6 & 6 \\
IQ-6: Educação Ambiental & 2 & 6 & 6 & 6 \\
IQ-7: Desenvolvimento institucional & 2 & 2 & 2 & 2 \\
IQ-8: Compatibilidade com outros planos & 2 & 6 & 2 & 4 \\
IQ-9: Qualificação dos servidores envolvidos com o PMSB & 4 & 4 & 4 & 4 \\
IQ-10: Diretrizes básicas Ministério das Cidades & 4 & 6 & 6 & 6 \\
\hline Média aritmética dos indicadores & 4,0 & 4,8 & 4,8 & 4,8 \\
\hline
\end{tabular}

Fonte: notas atribuídas pelas presentes autoras (2019) com base no Quadro 2.

O PMSB - D (Tabela 2) não apresentou informações sobre o controle social e sobre as estratégias de consolidação desta temática no plano (Figura 2). Isto é, faltou explicar a forma de participação da comunidade, bem como destacar a forma da população perceber os resultados com os objetivos e metas planejados.

Para ampliar o nível de Desenvolvimento Institucional, recomenda-se a realização de ações efetivas para elevar a qualificação de profissionais de órgãos públicos, tais como participação em cursos ou eventos para aprimoramento técnico e tecnológico em saneamento e gestão pública, estabelecimento de parceria com entidades de ensino e pesquisa para contribuir com esta capacitação, troca de experiências (benchmarking) com outras empresas do setor, uso de indicadores e softwares que ilustrem o aprimoramento de resultados a longo prazo.

A Figura 2 representa o desempenho dos dez indicadores no Dashboard (painel visual) por plano. 


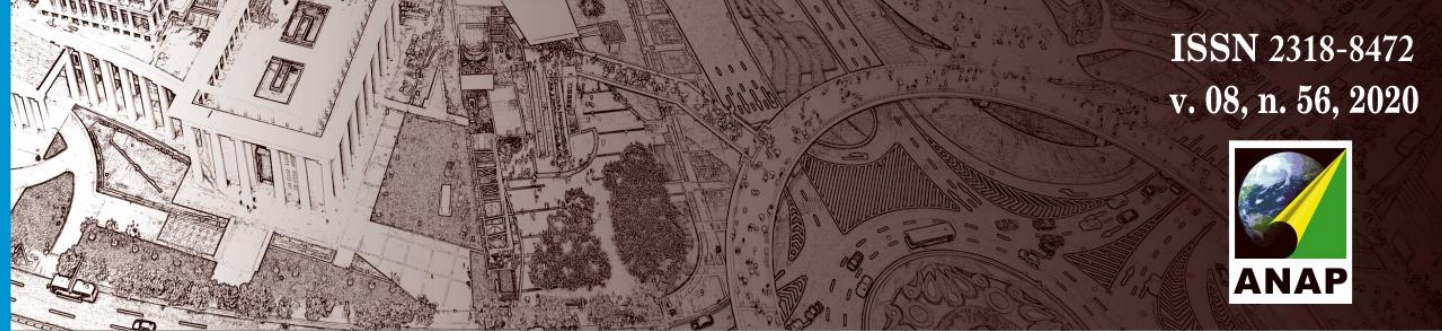

Revista Nacional de

Gerenciamento de Cidades

(Ventura e Farias, 2017), o que inviabiliza a avaliação do conteúdo e análise de dificuldades, pois o planejamento é o mesmo e o cenário é divergente.

Por fim, recomenda-se aos entes governamentais que sejam revistos os critérios para concessão de apoio financeiro aos municípios com planos elaborados, estabelecendo assim:

- Priorização de recursos garantida a municípios cujas particularidades foram contempladas no plano de saneamento;

- Participação social na elaboração e discussão dos planos de saneamento, garantindo o interesse no bem coletivo, seja ele municipal, regional ou consorciado;

- Avaliação periódica em períodos de 4 anos (duração mínima da gestão pública municipal) para os planos incorporarem novas estratégias e demanda factíveis a cada local.

O uso do método do Ministério das Cidades (2016) identifica somente a existência do conteúdo mínimo, mas não explora os resultados obtidos por cada municipalidade. Neste sentido, do ponto de vista científico, é salutar que novas pesquisas sejam direcionadas para a mensuração do desempenho das ações efetuadas a longo prazo, adotando indicadores qualitativos e quantitativos para esta comparação.

\section{CONCLUSÃo}

A avaliação dos Planos Municipais de Saneamento Básico (PMSBs) em quatro municípios (Charqueada/SP, Canápolis/MG, Iconha/ES e Moema/MG) da região sudeste do país foi realizada, considerando as intenções planejadas pelo poder público. Este estudo não abordou a análise das ações realizadas frente às almejadas.

De maneira geral, todos os PMSBs avaliados apresentaram atendimento medianamente satisfatório para o conteúdo mínimo estruturado, com média final entre 4,0 e 4,8.

Boa parte dos indicadores apresentaram melhor desempenho para os itens: participação da sociedade; diagnóstico dos serviços; objetivos, metas e ações; comitê gestor do PMSB; educação ambiental e, diretrizes dadas pelo Ministério das Cidades (2016).

$\mathrm{O}$ indicador que necessita de atenção em todos os planos avaliados foi o "Desenvolvimento Institucional" pela falta ou insuficiência de esclarecimentos deste indicador no material disponibilizado em meio digital.

Para elevar a nota deste indicador é essencial qualificar o quadro de pessoal e implantar medidas para fortalecer o instrumento público, tanto em equipamentos quanto em procedimentos de rotina para controle do serviço. Além disto, os municípios não esclarecem o papel das Agências Reguladoras, pois são elas que fiscalizam as ações do gestor dos serviços de saneamento e, assim, podem subsidiar a tomada de decisão do administrador público para novos investimentos.

É fundamental que os municípios busquem personalizar seus planos e, com isto, investir tempo e recursos financeiros suficientes para garantir qualidade no conteúdo destes documentos, sem 


